Rev. Latinoam. Psicopat. Fund., São Paulo, v. 14, n. 2, p. 222-236, junho 2011

\title{
Sobre a hipótese freudiana de histeroepilepsia de Dostoiévski*
}

Romina Moreira de Magalhães Gomes

Busca-se elucidar a leitura proposta por Freud sobre a histeroepilepsia de Dostoiévski, recorrendo-se aos textos, biografia e correspondência do escritor russo. A hipótese de ausência de epilepsia encontra limites, mas verifica-se que a relação de Dostoiévski aos representantes paternos tem papel decisivo em sua neurose, como construção sintomática para lidar com o desamparo.

Palavras-chave: Dostoiévski, histeroepilepsia, histeria, pai

* As reflexões contidas neste artigo iniciaram-se com a pesquisa que resultou em minha dissertação de mestrado intitulada "O amor que encobre a falha paterna: dos impasses na teoria freudiana do pai”, defendida em 2002, no Programa de Pós-Graduação em Psicologia da Universidade Federal de Minas Gerais (Belo Horizonte, MG, Brasil). 
O termo histeroepilepsia, proposto inicialmente por Charcot, foi empregado por Freud em sua leitura da obra, biografia e correspondência do escritor russo Dostoiévski. A palavra reúne dois termos da psicopatologia - histeria e epilepsia. Um deles, a epilepsia, designa uma patologia orgânica que produz efeitos na subjetividade. Já a histeria refere-se a um modo de constituição subjetiva cujos sintomas encenam um quadro orgânico, sem, no entanto, existirem alterações físicas subjacentes. Interessa-nos, neste artigo, retomar as elaborações freudianas visando esclarecer o emprego do termo que se refere às manifestações sintomáticas da subjetividade histérica, remetendo a um modo de constituição do aparelho psíquico.

Em uma carta dirigida ao escritor Stefan Zweig, em 19 de outubro de 1920, seis anos antes de iniciar a escrita do texto "Dostoiévski e o parricídio", Freud nos mostra que já vinha pensando no escritor russo e sua obra. Ao comentar o livro Três mestres: Balzac, Dickens e Dostoiévski, de Zweig, Freud o felicita pela leitura empreendida sobre os escritores Balzac e Dickens, apresentando, no entanto, uma discordância com relação à leitura proposta sobre Dostoiévski. Escreve Freud: "Com o maldito russo o sucesso teria que ser menor. Aqui se sentem os vazios e os enigmas não resolvidos" (Freud, 1982, p. 388). Ele propõe a hipótese, que será retomada em "Dostoiévski e o parricídio", de que o escritor russo não seria epiléptico, mas sim histérico. Do contrário, não seria possível entender o seu gênio artístico, uma vez que a epilepsia implicava, para os médicos da época, uma deterioração da inteligência.

Freud declara a Zweig que Dostoiévski "não pode ser compreendido sem a psicanálise - isto é, precisa dela porque ele próprio a ilustra em todos os personagens e em todas as frases" (p. 389). Dostoiévski representa, assim, um furo no saber, um enigma que somente a psicanálise permitiria elucidar.

Apesar de reconhecer o gênio artístico do escritor e aproximá-lo de Shakespeare, Freud não o inclui entre os seus escritores preferidos. Ao contrário, diz a Theodor Reik, em uma carta escrita em 1929: 
Você tem razão, também, em desconfiar de que, a despeito de toda minha admiração pela intensidade e preeminência de Dostoiévski, de fato não gosto dele. Isso se deve a que minha paciência com as naturezas patológicas está exaurida na análise. $\mathrm{Na}$ arte e na vida, não as tolero. Trata-se de traços caracterológicos que me são pessoais e não obrigam a outros. (p. 200)

O que Freud explicita dessa falta de admiração refere-se, sobretudo, ao desejo bruto e pulsional, ao masoquismo e ao amor por piedade, aos quais Dostoiévski se entrega. Ele percebe certa covardia do escritor na forma como este se posiciona frente aos representantes paternos.

Freud (1982) parece tomar a obra mais célebre do escritor russo como uma realização, pela via da arte, dos desejos proibidos de parricídio e de incesto. Pois, matar o pai é, para ele, um ato movido por um objeto incestuoso: a mãe. Mas é justamente Dostoiévski quem lhe mostra que os atos podem equivaler às intenções, ao atribuir a três dos irmãos Karamazov a culpa pelo assassinato do pai. Não é, pois, necessário que tenha havido um crime para que o sujeito se sinta culpado. Freud descobre que a presença da culpa pode, ao contrário, levar ao crime. Dostoiévski busca, entretanto, outra saída para inscrever seu intenso sentimento de culpa: o caminho da criação literária. Mas, esse caminho não o leva muito longe.

Freud (1927) considera que as lutas morais empreendidas pelo escritor russo não o levaram a um resultado glorioso. É justamente com relação a esse aspecto que irá colocar uma interrogação:

Depois das mais violentas lutas para reconciliar as exigências instintuais (Triebansprüche) do indivíduo com as reivindicações da comunidade, veio a cair na posição retrógrada de submissão à autoridade temporal e à espiritual, de veneração pelo czar e pelo Deus dos cristãos, e de um estreito nacionalismo russo - posição a que mentes inferiores chegaram com menor esforço. Esse é o ponto fraco dessa grande personalidade. Dostoiévski jogou fora a oportunidade de se tornar mestre e libertador da humanidade e se uniu a seus carcereiros. O futuro da civilização humana pouco terá por que lhe agradecer. Parece provável que sua neurose o tenha condenado a esse fracasso. A grandeza de sua inteligência e a intensidade de seu amor pela humanidade poderiam ter-lhe aberto outro caminho de vida, um caminho apostólico. (p. 183)

Assim, Freud aponta para certa covardia do sujeito, atribuindo o fracasso neurótico de Dostoiévski ao sentimento de culpa com o qual este se debateu até o final de sua vida. Isso pode ser demonstrado por sua vacilação entre tornar-se um religioso e permanecer ateu e, principalmente, pela aceitação de uma condenação injusta imposta pelo czar, que assume para ele o lugar de um representante paterno. 
Dostoiévski fora condenado por ter participado de reuniões em grupos de intelectuais que ganharam a reputação de politicamente subversivos. Quando certa vez lhe disseram que sua condenação havia sido injusta, ${ }^{1}$ ele objetou: “... talvez o Todo-Poderoso o tenha me enviado para que eu pudesse aprender a essência das coisas, a fim de comunicá-la ao próximo" (Fülop-Miller, 1954, p. 57). O único ato condenável empreendido por Dostoiévski foi a leitura de uma carta do crítico Bielinski escrita a Gogol, onde se podiam encontrar ideias subversivas (Arban, 1949). Mais tarde, em carta endereçada à sua esposa, ele declarou ter sido sua prisão "um providencial acidente" que o impediu de enlouquecer (Frank, 1999a).

Para que se possa avaliar a extensão da submissão de Dostoiévski à figura paterna, que ele encontra no czar, é interessante notar o fato de que o primeiro escrito a que ele se dedica, quando sai da prisão de Omsk, após seis anos de silêncio, é um poema comemorativo do aniversário da esposa de Nicolau I, o mesmo czar que fora responsável por sua condenação. ${ }^{2}$ Nesse poema, escrito em 1855, Dostoiévski afirma que o cumprimento da pena fez dele um homem:

Perdoai-me, perdoai-me, perdoai meu desejo. Perdoai-me por ousar dirigir-me a vós. Perdoai-me por ousar nutrir o insensato sonho de consolar vossa tristeza, de aliviar vosso sofrimento. Perdoai que eu, um pesaroso proscrito, ouse levantar minha voz ante este túmulo sagrado. Mas Deus! nosso juiz para toda a eternidade! Tu me enviaste Teu julgamento nas horas agitadas da dúvida, e com meu coração descobri que lágrimas são expiação, que outra vez eu era um russo e, outra vez - um homem! (Frank, 1999b, p. 278-279)

Dostoiévski confessa publicamente que a prisão serviu à expiação de sua culpa. Contudo, essa culpa não era devido a um ato, conforme ele mesmo assu-

1. Na ocasião da condenação de Dostoiévski, a comissão de inquérito responsável pelo caso concluiu pela não existência de uma sociedade subversiva de propaganda organizada. A condenação do escritor deveu-se a ele ter "alimentado projetos criminosos, por ter propagado a carta do escritor Bielinski repleta de ultrajes contra a Igreja Ortodoxa e o Poder Supremo, e por ter, ao mesmo tempo, desejado difundir as obras hostis ao governo" (Arban, 1949, p. XVII). Essa intenção de difundir obras hostis era uma referência à participação do escritor nos projetos de imprimir textos, como a carta de Bielinski, em uma litografia caseira (Frank, 1999b).

2. Foi esse mesmo czar que, em 1849, ordenou que se encenasse uma falsa cerimônia de execução de prisioneiros, dentre os quais o escritor se encontrava, e que instantes antes do fuzilamento ordenou a suspensão das mortes, enviando Dostoiévski à fortaleza de Omsk na Sibéria. Mas esse poema intitulado "Sobre o primeiro de julho de 1855" não parece ter sido a única demonstração de submissão ao czar. Numa carta a seu amigo Wrangel, escrita em 13 de abril de 1856, Dostoiévski faz referência a dois outros poemas patrióticos: "Sobre a morte de Nicolau I" e "Pelo aniversário da Imperatriz Alexandra Fedorovna", irmã do czar (Arban, 1949). 
me em uma carta escrita após o cumprimento da pena: "Eu era culpado. Reconheço-o integralmente. Fui condenado por ter a intenção (mas só a intenção) de agir contra o governo. Fui condenado legal e justamente" (p. 288). Constatamos, assim, que a equivalência entre as intenções e os atos que Freud lê em Dostoiévski, a partir de seu romance Os irmãos Karamazov, é experimentada no real pelo escritor russo. Sua prisão é providencial no sentido em que permite ligar a culpa presente de forma avassaladora a uma representação (a de uma ofensa ao czar), correspondendo, portanto, a uma fonte de certo alívio.

Freud questiona a posição de submissão ao pai, ou seja, a posição masoquista do escritor que se oferece em sacrifício aos representantes paternos. A proposta de que Dostoiévski seja um libertador pode, então, ser entendida como uma possibilidade de transmitir o ato de criação na qual este último não se encontre subordinado ao sacrifício ao pai. Nesse sentido, Freud nota que o escritor só podia criar após ter perdido tudo no jogo, após ter se consumido como sujeito em seu sacrifício à instância paterna.

Ao se deter frente à posição masoquista de Dostoiévski, Freud está interrogando o amor ao pai, pois ele considera que a união do amor à pulsão de morte determina a posição masoquista do filho. O que impede de colocarmos Dostoiévski entre os criminosos é justamente a sua grande necessidade de amor e a sua enorme capacidade de amar. Mas é também devido a esse amor que o escritor fracassa. A presença proeminente da culpa tem aqui um papel no destino fracassado do amor em sua neurose. Na carta a Reik, de 1929, Freud ressalta o surpreendente desamparo do escritor diante das manifestações do amor. É no encontro dessa dimensão com a pulsão destrutiva que é possível situar o seu masoquismo. A neurose de Dostoiévski soluciona a contradição da presença simultânea do amor intenso e das tendências agressivas, dirigindo a pulsão destrutiva para ele mesmo, encontrando expressão no masoquismo e no sentimento de culpa, ambos representando traços marcantes que caracterizam a sua posição subjetiva.

A posição masoquista do escritor russo tem, para Freud, uma relação estreita com a figura paterna. O assassinato do pai de Dostoiévski é colocado em um plano central, como uma experiência dilaceradora vivida por ele aos dezoito anos de idade. Seu pai costumava impor aos filhos a sua vontade caprichosa. ${ }^{3}$ Ele exigia que Dostoiévski buscasse uma carreira segura em termos financeiros, levando o fi-

3. Conforme aponta Frank, biógrafo do escritor, “... as poucas informações disponíveis sobre Dostoiévski nessa época [por volta de 1836, época que antecede o assassinato do pai, ocorrido em 1839] sugerem que, desde muito cedo, ele começou a impacientar-se com (...) a necessidade de ceder à inflexível rigidez e à instabilidade emocional de um pai que identificava seus desejos pessoais com os ditames do próprio Deus" (Frank, 1999a, p. 68). 
lho a ingressar na Academia de Engenharia Militar de São Petersburgo. Quando ele morre, Dostoiévski se vê liberado para seguir a carreira de escritor pela qual há muito se interessava. Porém, o que ocorre na vida desse promissor homem de letras após a morte de seu pai é uma turbulenta rotina que começa pela condenação a quatro anos de trabalhos forçados na Fortaleza de Omsk, seguido de um vício pelas mesas de jogo e dívidas intermináveis, as quais não eram frutos somente desse vício, mas também de uma desconcertante ingenuidade para lidar com questões financeiras. ${ }^{4}$ Essa rotina se conjuga a uma longa espera pelo sucesso que só chega de fato ao final de sua obra, com a publicação de Os irmãos Karamazov.

Dentre os aspectos que se destacam na vida de Dostoiévski, o mais polêmico é o da sua epilepsia. Não só a data do aparecimento das crises é controversa, mas também, após a leitura de Freud, o próprio estatuto da doença é colocado em questão: trata-se de uma epilepsia - doença orgânica - ou trata-se de uma histeroepilepsia, ou seja, de uma neurose histérica? Com esse questionamento, Freud reduz a doença do escritor a um dos sintomas de sua neurose. Ele não hesita em tocar naquilo que alguns biógrafos com certa tendência à hagiografia consideram intocável. Sob esse ponto de vista, Freud não cede ao pudor, dispondo-se a revirar os fatos para deles extrair algo que possa fazer avançar sua leitura e, consequentemente, a teoria.

Freud (1927) se diz inclinado a ver na morte do pai um trauma, tomando a reação de Dostoiévski a esse acontecimento como desencadeador de sua neurose e das crises epilépticas. Contudo, antes de as convulsões terem iniciado, ele passou por crises que surgiam "sob a forma de uma melancolia súbita e infundada, uma sensação, como mais tarde contou a seu amigo Soloviev, de que iria morrer ali mesmo" (p. 188). Andrei Dostoiévski, irmão do escritor, conta que Fiódor espalhava bilhetinhos pela casa antes de dormir, por temer cair em um sono semelhante à morte, e pedia que só fosse enterrado após um período de cinco dias. O aparecimento dessas crises leva Freud a considerar a existência de uma identificação a uma pessoa morta ou a alguém cuja morte é desejada. Freud recorre, neste ponto, à ligação, já antes estabelecida por alguns biógrafos do escritor, entre o assassinato do pai em Os irmãos Karamazov e a morte do próprio pai de Dostoiévski. Tais crises ganham, assim, um valor de autopunição pelo desejo de

4. Dostoiévski costumava aceitar quantias irrisórias por seus trabalhos como escritor, deixava-se endividar e explorar por seus credores, os quais lhe cobravam quanto queriam e, mesmo cheio de dívidas, mantinha as despesas da casa de seu falecido irmão que deixara mulher e filhos, além de arcar com as despesas de seu enteado, filho de sua primeira mulher. Isso tudo contribuía para que suas dívidas assumissem proporções enormes, as quais só pôde saldar pouco antes de sua morte. Conferir Dostoievskaia (1999). 
morte do pai que é objeto de ódio, significando também uma identificação com o pai morto, já que para o eu o sintoma da morte significa uma satisfação masoquista e para o supereu, uma satisfação sádica, punitiva. Este é, segundo Freud, o novo palco, estabelecido a partir do recalcamento, onde se encenará no sujeito a relação com o pai.

As dúvidas do escritor russo quanto à existência de Deus podem ser lidas, de acordo com Freud (1927), como um desejo de destruir o pai que convive com a tentativa de preservá-lo, denunciada pela sua submissão aos caprichos da figura paterna.

Freud trabalha assim com a hipótese de que Dostoiévski era histérico, sendo sua epilepsia apenas um sintoma de sua histeria, mostrando, ao mesmo tempo, a presença de traços masoquistas intensos que caracterizam sua posição subjetiva, os quais aparecem ao longo da obra e biografia do escritor. Percorrendo o texto Dostoiévski e o parricídio e a biografia de Dostoiévski, constatamos, no entanto, que Freud não dispunha de elementos suficientes para afirmar que ele não era epiléptico, ${ }^{5}$ o que não invalida a sua hipótese de que ele seria histérico.

$\mathrm{Na}$ biografia de Dostoiévski, encontramos que a primeira crise de epilepsia diagnosticada por um médico aconteceu em 1850, na prisão de Omsk, na Sibéria. Mas já em 1846, há registros de "crises nervosas" e desmaios do escritor, quando Dostoiévski começou a ser criticado e ironizado por Bielinski, após a publicação de $O$ sósia (1846). Entretanto, foram as críticas de Turguiênev que surtiram um efeito mais devastador em Dostoiévski. Juntamente com Nekrassov, ele escreveu um poema intitulado "O cavaleiro da triste figura", onde ironizava a alta conta em que o próprio Dostoiévski se tinha, qualificando-o de "uma pústula no rosto da literatura russa" (Frank, 1999a, p. 224). ${ }^{6}$

A epilepsia de Dostoiévski foi objeto de estudo de vários neurologistas, tendo a maior parte deles diagnosticado a doença como uma epilepsia motora do lobo

5. Conforme o próprio Freud definira em seu verbete Histeria, escrito em 1888, na verdadeira epilepsia, os ataques são seguidos de um cansaço e de um sono intenso, o que não ocorre na histeroepilepsia. De acordo com o relato de sua segunda esposa, Dostoiévski era tomado por um extremo cansaço e mau humor, quando terminavam suas crises, chegando a ficar sonolento e a dormir por dias a fio (Dostoievskaia, 1999). Esse é um dos aspectos que vai de encontro às hipóteses formuladas por Freud com relação à epilepsia do escritor. O próprio Freud chega a admitir no texto Dostoiévski e o parricídio que não possuía elementos para levar adiante a hipótese da inexistência de uma epilepsia no caso.

6. Contudo, o assunto é verdadeiramente controverso. O primeiro biógrafo de Dostoiévski, Orest Miller, que foi amigo íntimo do escritor, afirma que "há uma tradição ligando a doença de Dostoiévski a um acontecimento atormentador sobrevindo na vida de seus pais, quando Dostoiévski era ainda uma criança" (Arban, 1949, p. XII). Miller situa a primeira crise epiléptica do escritor na sequência desse acontecimento. Outro biógrafo, Leonid Grossmann, re- 
temporal. Entretanto, em 1977, Henri Gastaut questionou esse diagnóstico, tendo em vista o caráter atípico da aura do escritor. Gastaut realizou um extenso estudo no qual encontrou que, em todas as descrições relatadas por médicos sobre auras epilépticas, ressaltavam-se as características "alarmante e assustadora”. No século XX, quando Dostoiévski já se tornara conhecido, assim como seu romance $O$ idiota, onde ele descreve o êxtase do personagem Mychkin na aura epiléptica, é que surgiram alguns raros casos de auras com características agradáveis e eufóricas. Surpreendentemente, Gastaut chegou à conclusão de que as auras extáticas não existiam e que Dostoiévski, em meio à confusão de seu estado de consciência, deturpara as próprias sensações ao descrevê-las. Assim, a controvérsia sobre a aura extática do escritor permaneceu (Frank, 1999b).

Mas, uma vez verificada a insuficiência e a natureza controversa dos dados relativos à epilepsia de Dostoiévski, por que Freud não abre mão da hipótese de histeroepilepsia, insistindo, ao contrário, num certo valor neurótico da doença do escritor? Cabe notar que na leitura proposta sobre Dostoiévski os dotes artísticos do escritor permanecem inacessíveis, inanalisáveis, juntamente com a sua disposição pulsional inata (die perverse Triebanlage). Freud terá, assim, que colocar de lado esses dois aspectos qualitativos para se concentrar no fator quantitativo: a intensidade da vida emocional do escritor. É, dessa forma, o ponto de vista econômico que se encontra em questão em sua leitura do caso Dostoiévski.

Fazendo uma analogia entre as crises epilépticas e as crises histéricas, Freud retoma a comparação entre as neuroses e as intoxicações já realizada anteriormente. Em 1896, numa das cartas dirigidas a Fliess, afirma: "Sempre entendi os processos das neuroses de angústia, bem como das neuroses em geral, como uma intoxicação" (Masson, 1986, p. 181). Em "Três ensaios sobre a teoria da sexualidade", ele prossegue com a analogia:

lata uma conversa que teve com a segunda mulher do escritor, Anna Grigorievna, em 1921, em que esta confirma a veracidade da relação estabelecida por Miller entre a epilepsia e esse evento da infância (p. XII). A francesa Dominique Arban situa a primeira crise, presenciada por um amigo do escritor, duas semanas após a morte de seu pai (1839), quando Dostoiévski, caminhando pelas ruas de São Petersburgo, deparou-se com o cortejo de um funeral e teve um desmaio (p. XIV). Já outro biógrafo mais recente, Joseph Frank (1999a), rejeita a polêmica acerca do início das crises, situando-a em 1850, e discorda da questão levantada por Freud acerca do estatuto da doença do escritor, apoiando-se no fato de que um filho de Dostoiévski morreu aos três anos de idade, com o diagnóstico de uma crise epiléptica fulminante, o que aponta para o caráter orgânico da doença, ou seja, para uma transmissão hereditária. Frank acusa Freud de ter construído "uma lenda em torno da infância de Dostoiévski”, no que se refere à origem das crises do escritor. 
As neuroses, que só podem ser atribuídas a perturbações na vida sexual, mostram a mais extrema semelhança clínica com os fenômenos de intoxicação e abstinência decorrentes do uso habitual de substâncias tóxicas produtoras de prazer. (Freud, 1905, p. 205)

A analogia remete, assim, à ideia de um elemento estranho que perturba a vida sexual. E sugere também a existência de um valor de tóxico próprio ao mecanismo da neurose, no sentido de algo que permanece fixado na economia libidinal do neurótico, algo de que ele não se dispõe a abrir mão. Em "Dostoiévski e o parricídio", Freud (1927) retoma a analogia, colocando a crise epiléptica a serviço da exigência de descarga devido a um excesso de excitação na economia da neurose:

É como se tivesse sido disposto organicamente um mecanismo para a descarga instintual (Triebabfuhr) anormal, de que se poderia fazer uso em circunstâncias inteiramente diferentes, tanto no caso de distúrbios de atividade cerebral devido a graves afecções histolíticas ou tóxicas quanto no de um controle inadequado sobre a economia mental, e, às vezes, quando a atividade da energia que opera na mente atinge o ponto de crise. Por trás dessa dicotomia, temos um vislumbre da identidade do mecanismo subjacente de descarga instintual. (p. 186)

Assim, o mecanismo da neurose, que consiste em livrar-se, pela via somática, do excesso de excitação com o qual o aparelho psíquico não tem meios de lidar, encontra uma via de descarga na "reação epiléptica". A origem dos processos sexuais que se encontram em jogo na histeria pode ser descrita como tóxica. Freud lembra que os médicos antigos costumavam comparar o coito a uma pequena epilepsia, tendo em vista o caráter convulsivo do orgasmo, reconhecendo, então, "o ato sexual como uma mitigação e adaptação do método epiléptico de descarregar estímulos" (p. 186). Na realidade, para Freud, a analogia da neurose com a reação epiléptica vem lançar luz sobre as vicissitudes do excesso de excitação com o qual o aparelho psíquico tem que se haver: o escoamento do excesso tendo um papel nessa economia, uma vez que se manifesta como um sintoma. Embora possa, à primeira vista, parecer que o escoamento visa unicamente livrar-se da energia retida, seu papel principal é, antes, reiterar certo estado de coisas, ou seja, uma satisfação.

A despeito de toda controvérsia em torno da epilepsia de Dostoiévski, a própria fala do escritor vem elucidar a pertinência das considerações de Freud no que se refere à satisfação em jogo na neurose, apontando para o papel dado à epilepsia em sua economia libidinal. Dostoiévski concebe sua doença como "um doloroso dom de Deus", seu "mal sagrado" e, descrevendo o estado de êxtase próprio à sua aura epiléptica, afirma: “... acredite-me, eu não a trocaria por todos os prazeres da vida. Até mesmo estaria disposto a trocá-la pela minha vida 
inteira" (Fülop-Miller, 1954, p. 60). Ao falar de sua epilepsia como um presente divino atrelado à dor, um mal que ele não trocaria por sua própria vida, preferindo a morte a ficar sem ele, o escritor nos coloca diante do que constitui, por excelência, o campo de atuação da psicanálise: o insuportável do qual, paradoxalmente, não se quer abrir mão.

Freud estabelece uma vinculação entre a felicidade suprema experimentada por Dostoiévski na aura epiléptica e o sentimento de liberação pela morte do pai, seguida de uma punição na forma da crise. Desse modo, o arrebatamento típico da aura do escritor encontra-se ligado, para Freud, à morte do pai. A aceitação por parte de Dostoiévski da punição imerecida imposta pelo czar aparece "como um substituto da punição que merecia por seu pecado contra o pai real" (Freud, 1927, p. 191). Com essa punição, por parte de um representante paterno, o sujeito se poupa de ter de punir a si mesmo, devido às exigências impostas pelo supereu.

Os relatos de Dostoiévski sobre sua aura aproximam-se de seu arrebatamento diante da figura de Cristo, conforme conta seu amigo Wrangel, que viveu junto com ele no seu período de exílio (Frank, 1999b). Sobre sua relação a Cristo, numa carta dirigida à esposa de um de seus amigos condenados à prisão na Sibéria, Dostoiévski relata:

Deus me envia, por vezes, instantes em que eu fico inteiramente tranquilo; nesses instantes, eu amo e me sinto amado pelos outros, e é nesses instantes que eu criei em mim um Credo onde tudo é claro e sagrado para mim. Esse credo é muito simples: crer que não há nada de mais belo, de mais profundo, de mais agradável, de mais razoável, de mais viril e de mais perfeito que Cristo; eu falo a mim mesmo com um amor não somente ciumento que não há nada mais, mas que não tem como haver. Mais ainda, se alguém me provasse que Cristo está fora da verdade, e se ficasse provado que a verdade não está em Cristo, eu preferiria então ficar com Cristo a ficar com a verdade. (Arban, 1949, p. 157)

Conforme aponta Freud, Dostoiévski parecia esperar encontrar uma saída para seu sentimento de culpa no ideal cristão, tomando a figura de Cristo como uma referência identificatória, ao assumir o papel de um sofredor.

Dostoiévski (1873-1880) concebe o amor como sendo estreitamente ligado ao sofrimento, conforme ele afirma em seu Diário de um escritor: "Na nossa [terra] somente se ama em meio à dor e pela dor e não conhecemos outro amor" (p. 165). Essa afirmação indica a direção a ser tomada para entendermos o fracasso neurótico do escritor, ligado ao masoquismo e ao sentimento de culpa.

Seguindo essa trilha, encontramos em Dostoiévski algumas peculiaridades que ajudam a pensar a sua relação com o sofrimento. Cedo em sua vida, ele começou a se interessar pelos enigmas colocados pela religião cristã, como a relação de Deus com o homem e a existência da dor, do mal, do sofrimento. Ainda quando 
criança, tornou-se leitor e admirador apaixonado do Livro de Jó (Frank, 1999a). Esse texto, que faz parte do Antigo Testamento, trata de um drama que opõe Deus ao homem. Para colocar à prova a fé de Jó, homem justo e reto, Deus o confia a Satanás. Jó sofre de todas as formas possíveis a dor de um mal injustificado. Ele se debate com o flagelo imerecido, proclamando a própria inocência, e busca em vão uma explicação para os seus sofrimentos. Ao final do drama, Deus aparece a Jó para mostrar o quanto é inútil questionar as ações divinas e o louva por não ter aceitado falsas respostas (Bíblia, 1962). Dessa forma, o que se revela a Jó é que o sofrimento comporta um não senso irredutível, mas também intocável, pois uma vez que faz parte dos desígnios de Deus, não deve ser questionado. Esse livro foi para Dostoiévski uma espécie de guia, segundo o que ele nos indica em carta dirigida à sua segunda mulher:

Eu li o Livro de Jó, que suscita em mim um êxtase quase mórbido. Eu o largo e caminho de um lado para o outro, durante horas, com pena de conter as minhas lágrimas. Esse livro, Anna, - não é estranho? - é um dos primeiros que me marcou para a vida. (Fülop-Miller, 1954, p. 72)

Segundo Freud, Dostoiévski jamais se libertou de seu sentimento de culpa, tendo se tornado extremamente submisso e reacionário em suas ideias políticas. Ele nos mostra, dessa maneira, que há, no sintoma de Dostoiévski, uma satisfação à qual ele se apega de forma incondicional, a despeito do sofrimento que acarreta. Essa satisfação paradoxal liga-se, para o escritor russo, à figura paterna, dentre as quais Deus se coloca como uma exigência inelutável, apesar das dúvidas manifestadas quanto à sua existência.

No romance Os irmãos Karamazov, Freud encontra vários elementos que servem de substrato à sua leitura. Dentre as figuras do pai encontradas no texto do escritor russo, encontra-se aquela que prega a possibilidade de salvação da alma pela absorção da culpa de todos, prometendo o acesso a um amor universal insaciável. O stáriets Zósima aproxima-se da figura de um santo, um pai idealizado, ao qual os religiosos são capazes de entregar as próprias vidas.

Já a personagem do velho Karamazov permite colocar em suspeita o estatuto do pai e questioná-lo como sistema (Saliba, 1996), na medida em que o amor que o faz existir não é dado naturalmente. O dever natural de amor ao pai é tomado, por Dostoiévski, como um preconceito místico, colocando em suspeição o caráter necessário de seu estabelecimento.

Entretanto, ao mesmo tempo em que inscreve essa suspeição, Dostoiévski defende a tese, exposta por meio das personagens Ivan Karamazov e stáriets Zósima, de que se não existe Deus, tudo é permitido, sugerindo que Deus contempla uma normatividade insubstituível, sem a qual não pode passar uma comunidade humana. As raízes dessa ideia que é expressa com clareza em Os irmãos 
Karamazov (1880) podem ser encontradas já em Crime e castigo (1866). Raskólnikov, personagem desse livro, concebe o crime como uma questão de aritmética, este podendo representar até um favor à humanidade por permitir um melhor uso do dinheiro que era guardado pelo morto. Aqui, já encontramos também a ideia, expressa em Os irmãos Karamazov e apontada por Freud, de que aquele que despreza a lei pode ser menos um criminoso repugnante do que um felicitado benfeitor. Mas, na medida em que o crime tem o efeito de retirá-lo do laço social, colocando-o diante do insuportável, Raskólnikov, a despeito de sua falta de remorso, acaba por se converter ao cristianismo e aceita, devido ao amor, a pena pelo crime cometido encontrando assim uma promessa de solução para o desamparo.

No romance Os irmãos Karamazov, o ideal cristão reaparece como saída ao desamparo. É o que Aliócha, como herói apontado pelo autor, vem mostrar. Se a busca por um ideal no exército fracassa - no caso de Dimítri - assim como fracassa quando é procurado no terreno da razão - no caso de Ivan e do próprio velho Karamazov que também se diz ateu -, Dostoiévski aposta todas as suas fichas na Igreja.

A leitura de Freud nos mostra o papel de redentor que o criminoso adquire no texto de Dostoiévski. Ele é tomado como um herói, por ser capaz de suplantar o poder paterno. Nesse sentido, Freud considera que Dimítri, o filho que é arrastado por suas paixões, é o herói da trama, por ter se revelado, aos olhos de todos, capaz de matar o pai.

Frente a essa ameaça de liberação do gozo pelo crime, Dostoiévski recorre a Deus como única ordem capaz de conter essa liberação. Tomando Deus como uma das figuras do pai, tal como Freud o faz, podemos ler na afirmação do escritor russo se não existe Deus, tudo é permitido, que ele se mantém colado ao pai, como uma exigência de normatividade. Freud, por outro lado, considera em "Totem e tabu" que, diante da inexistência de Deus, a interdição à satisfação pulsional é reforçada, e não liberada como Dostoiévski parece supor.

De fato, do ponto de vista neurótico, não há como permanecer tranquilo e seguro ao se colocar em questão o sistema pai. Ao fazê-lo, o neurótico se depara com a experiência dispersiva do desamparo. Sua resposta é, então, o masoquismo. Enquanto a relação ao pai é ambivalente, ultrapassá-lo não é algo que se possa desejar impunemente. Dostoiévski o atesta com sua vida e obra.

\section{Referências}

Arban, D. Correspondance de Dostoiévski. Paris: Calman-Lévy, 1949. Tome I. 
Bíblia. Edição Especial Comentada. Rio de Janeiro: Livros do Brasil, 1962. V. 1. DostoievskaiA, A.G. (1911-1916). Meu marido Dostoiévski. Rio de Janeiro: Mauad, 1999.

Dostolévski, F.M. (1866). Crime e castigo. Rio de Janeiro: Tecnoprint, s.d. . (1873-1880). Diário de um escritor. Rio de Janeiro: Tecnoprint, s.d. . (1880). Os irmãos Karamazov. Rio de Janeiro: Tecnoprint, s.d.

Frank, J. (1821-1849). Dostoiévski, as sementes da revolta. São Paulo: Edusp, 1999a. . (1850-1859). Dostoiévski, os anos de provação. São Paulo: Edusp, 1999b.

Freud, S. (1905). Três ensaios sobre a teoria da sexualidade. In: Edição Standard Brasileira das Obras Psicológicas Completas de Sigmund Freud. Rio de Janeiro: Imago, 1996. V. 7, p. 119-229.

. (1912-1913). Totem e tabu. In: Edição Standard Brasileira das Obras Psicológicas Completas de Sigmund Freud. Rio de Janeiro: Imago, 1996. V. 13, p. 13-162.

. (1927). Dostoiévski e o parricídio. In: Edição Standard Brasileira das Obras Psicológicas Completas de Sigmund Freud. 2. ed. Rio de Janeiro: Imago, 1987. V. 21, p. $181-200$.

. Uma carta de Freud a Theodor Reik (14/4/1929). In: Edição Standard Brasileira das Obras Psicológicas Completas de Sigmund Freud. 2. ed. Rio de Janeiro: Imago, 1987. V. 21, p. 199-200.

. Correspondência de amor e outras cartas - 1873-1939. Rio de Janeiro:

Nova Fronteira, 1982.

FüLoP-Miller, R. Dostoeïvski: l'intuitif, le croyant, le poète. Paris: Éditions Albin Michel, 1954.

Masson, J.M. A correspondência completa de S. Freud para Wilhelm Fliess - 18871904. Rio de Janeiro: Imago, 1986.

Saliba, A. M. P. O jogo do pai. Alétheia, Governador Valadares, n. 1, p. 10-15, 1996.

\section{Resumos}

(On Freud's hypothesis about Dostoyevsky's hystero-epilepsy)

This paper discusses Freud's reading of Dostoyevsky's hystero-epilepsy, based on this latter's literary production, biography and correspondence. The hypothesis that there was no epilepsy has its limits, but we found that the relationship between 
Dostoyevsky and father figures did play a crucial role in his neurosis, which served as a symptomatic construction to deal with his helplessness.

Key words: Dostoevsky, hystero-epilepsy, hysteria, father

(Sur l'hypothèse freudienne de l'hystéro-épilepsie de Dostoïevski)

Dans cet article, nous cherchons à élucider la lecture proposée par Freud sur l'hystéro-épilepsie de Dostoïevski en nous référant aux écrits, à la biographie et à la correspondance de l'écrivain russe. L'hypothèse de l'absence de l'épilepsie a ses limites, mais nous vérifions que le rapport entre Dostoïevski et les représentants paternels joue un rôle décisif dans sa névrose en tant que construction symptomatique pour faire face à l'impuissance.

Mots clés: Dostoïevski, hystéro-épilepsie, hysterie, père

(Acerca de la hipótesis freudiana de histeroepilepsia de Dostoievski)

El artículo se propone a dilucidar la lectura propuesta por Freud a respecto de la histeroepilepsia de Dostoiesky recurriendo a textos, biografia y correspondência del escritor ruso. La hipótesis de ausencia de epilepsia es limitada, aunque se encuentra que la relación de Dostoiesky com los representantes paternos tienen um papel decisivo em su neurosis, como uma construcción sintomática para hacer frente al desamparo.

Palabras clave: Dostoievski, histeroepilepsia, histeria, padre

Citação/Citation: Gomes, R.M.M. Sobre a hipótese freudiana de histeroepilepsia de Dostoiévski. Revista Latinoamericana de Psicopatologia Fundamental, São Paulo, v. 14, n. 2, p. 222-236, jun. 2011.

Editor do artigo/Editor: Prof. Dr. Manoel Tosta Berlinck

Recebido/Received: 18.6.2010 / 6.18.2010 Aceito/Accepted: 25.9.2010 / 9.25.2010

Copyright: (C) 2009 Associação Universitária de Pesquisa em Psicopatologia Fundamental/ University Association for Research in Fundamental Psychopathology. Este é um artigo de livre acesso, que permite uso irrestrito, distribuição e reprodução em qualquer meio, desde que o autor e a fonte sejam citados/This is an open-access article, which permits unrestricted use, distribution, and reproduction in any medium, provided the original author and source are credited.

Rev. Latinoam. Psicopat. Fund., São Paulo, v. 14, n. 2, p. 222-236, junho 2011 
Financiamento/Funding: A autora declara não ter sido financiada ou apoiada/The author has no support or funding to report.

Conflito de interesses/Conflict of interest: A autora declara que não há conflito de interesses/The author declares that has no conflict of interest.

\section{Romina Moreira de Magalhães Gomes}

Psicanalista; Mestre em Psicologia, área de concentração em Estudos Psicanalíticos, pela Universidade Federal de Minas Gerais (Belo Horizonte, MG, Brasil); Psicóloga Judicial do Núcleo Supervisor do Programa de Atenção Integral ao Paciente Judiciário Portador de Sofrimento Mental (PAI-PJ) do Tribunal de Justiça de Minas Gerais (Belo Horizonte, MG, Brasil).

Rua Fernandes Tourinho, 735/901 - Lourdes

30112-000 Belo Horizonte, MG, Brasil

Fone: (31) 3289-2200

e-mail: rominagomes@hotmail.com 